\title{
Micropropagation of Strawberry cv. Camarosa: Prolific Shoot Regeneration from In Vitro Shoot Tips Using Thidiazuron with N6-benzylamino-purine
}

\author{
Fatemeh Haddadi and Maheran Abd Aziz ${ }^{1}$ \\ Department of Agriculture Technology, Faculty of Agriculture, Universiti \\ Putra Malaysia, 43400 Serdang, Selangor, Malaysia
}

Ghizan Saleh

Department of Crop Science, Faculty of Agriculture, Universiti Putra Malaysia, 43400 Serdang, Selangor, Malaysia

\section{Azmi Abd Rashid and Hossein Kamaladini \\ Department of Agriculture Technology, Faculty of Agriculture, Universiti Putra Malaysia, 43400 Serdang, Selangor, Malaysia}

Additional index words. MS medium, TDZ, BAP, IBA, NAA, Hoagland's solution

\begin{abstract}
An efficient micropropagation system for strawberry cv. Camarosa was developed. Sterilized runner tips were cultured on hormone-free Murashige and Skoog (MS) medium with $3 \%$ sucrose, $1 \mathrm{~mL} \cdot \mathrm{L}^{-1}$ Plant Preservative Mixture, and solidified using $0.25 \%$ phytagel to produce in vitro stock plants. Shoot tips derived from the in vitro stock plants were cultured on MS media containing $0,2,4$, and $8 \mu M$ thidiazuron (TDZ) and 0 , $4,9,18$, and $27 \mu M$ N6-benzylamino-purine (BAP) for shoot induction. Shoots produced on the best shoot induction medium were rooted on MS media containing 1, 2, 3, and $5 \mu M$ of either indole-3-butyric acid (IBA) or naphthaleneacetic acid (NAA). Results showed that MS medium with $2 \mu M$ TDZ and $4 \mu M$ BAP was optimum for shoot multiplication from the shoot tips. The most suitable medium for inducing the highest number of roots per explant, the highest percentage of explant with roots, and the highest mean root length were $1 \mu M$ NAA, $1 \mu M$ IBA, and hormone-free MS medium, respectively. Plantlets were transplanted into substrate consisting of perlite + vermiculite + cocopeat $(2: 1: 2 \mathrm{v} / \mathrm{v} / \mathrm{v})$ resulting in $90 \%$ survival. After 1 month, plants were irrigated using Hoagland's solution and runners were produced after 3 months.
\end{abstract}

Strawberry is usually propagated vegetatively using runners to obtain true-to-type plants. The success of strawberry planting depends on the availability of large numbers of runners and good planting stock. In vitro propagation system provides an alternative and novel possibility of enhancing the production of planting materials, including virus-free plants for large-scale planting. The establishment of an efficient in vitro regeneration system in strawberry could also make a significant contribution in improving the qualitative and quantitative characters of the plant. Since the first report on in vitro strawberry propagation by Boxus (1974), there have been many reports on types of medium, plant growth regulators, genotypes, and types of explants used in strawberry regeneration. Nevertheless, there are still problems associ-

Received for publication 7 Oct. 2009. Accepted for publication 17 Dec. 2009.

This research was supported by RUGS project no. 01/01/07/0300RU.

We gratefully acknowledge the excellent assistance of Professor Barbara M. Reed.

${ }^{1}$ To whom reprint requests should be addressed; e-mailmaheran@agri.upm.edu.my. ated with the regeneration of strawberry explant; for example, the highest percentage of explant producing shoots for cv. Elsanta was only 4\% (Debnath, 2006), which seems to be insufficient for commercialization.

Cytokinins are known to play a major role in controlling shoot branching. To date, N6benzylamino-purine (BAP) is the cytokinin that is mostly used on in vitro shoot proliferation of strawberry. In contrast, thidiazuron (TDZ) is the cytokinin of more recent use for shoot regeneration in a restricted number of strawberry cultivars (Landi and Mezzetti, 2006; Passey et al., 2003). TDZ was used for shoot regeneration of strawberry either alone (Mohamed et al., 2007; Sutter et al., 1997; Svensson and Johansson, 1994) or in combination with auxins like indole-3butyric acid (IBA) (Landi and Mezzetti, 2006; Yonghua et al., 2005). However, there are no reports so far on the effect of TDZ in combination with other types of cytokinins on shoot regeneration of strawberry. Therefore, in the present study, the effect of TDZ as a phenylurea-type cytokinin in combination with BAP as an adenine-type cytokinin on shoot regeneration from in vitro shoot tips of strawberry cv. Camarosa was investigated.
Two types of auxins, IBA and naphthaleneacetic acid (NAA), in different concentrations, were assessed for root induction. 'Camarosa' strawberry is a cultivar that is popularly grown in Cameron Highlands, Malaysia. The availability of an efficient micropropagation protocol for 'Camarosa' strawberry developed in this study may assist in overcoming the shortage of runners as planting materials often faced by farmers in Cameron Highlands.

\section{Materials and Methods}

Plant material and sterilization protocol. Runner tips measuring $1 \mathrm{~cm}$ in length were collected from 1-year-old glasshouse 'Camarosa' strawberry plants growing in the Cameron Highlands region (long. 4'28'60" $\mathrm{N}$, lat. $101^{\circ} 27^{\prime} 0^{\prime \prime} \mathrm{E}$, elevation: $1448 \mathrm{~m}$ ) of Malaysia. Sterilization of runner tips was carried out following the protocol of Bhatt and Dhar (2000) with some modifications. The runner tips were first rinsed under running tap water for $1 \mathrm{~h}$ and then surfacesterilized by immersing and shaking them in 2\% Teepol for 5 min followed by immersing and shaking in 3\% Savlon for $15 \mathrm{~min}$. The sterilized tips were next rinsed with sterile distilled water once, disinfected by immersing and shaking in $80 \%$ ethanol for $1 \mathrm{~min}$, and followed by immersing and shaking in $0.05 \% \mathrm{HgCl}_{2}$ plus a few drops of Tween 20 for $5 \mathrm{~min}$. Finally, the explants were rinsed with sterile distilled water three to five times. The sterilized tips were then cultured in 250-mL Erlenmeyer flasks containing $40 \mathrm{~mL}$ of Murashige and Skoog (MS) medium (Murashige and Skoog, 1962) with 3\% sucrose, $1 \mathrm{~mL} \cdot \mathrm{L}^{-1}$ Plant Preservative Mixture (Phytotechnology Laboratories, Shawnee Missions, KS), and solidified using $0.25 \%$ phytagel (Sigma Company, St. Louis, MO). Two runner tips were cultured in each Erlenmeyer flask. Each culture was incubated at $25 \pm 2{ }^{\circ} \mathrm{C}$ under a $16-\mathrm{h}$ photoperiod of $40 \mu \mathrm{mol} \cdot \mathrm{m}^{-2} \cdot \mathrm{s}^{-1}$ fluorescent light for 6 weeks to produce in vitro stock plants. Shoot tips were finally collected from the stock plants and used for the study.

Shoot induction. Shoot tips measuring 5 to $8 \mathrm{~mm}$ were collected from the in vitro stock plants (Fig. 1A) and cultured as described previously on MS medium containing $0,2,4$, and $8 \mu \mathrm{M}$ TDZ in combination with $0,4,9$, 18 , and $27 \mu \mathrm{M}$ BAP. The tips were subcultured three times on each medium at 4-week intervals over a period of 12 weeks. Each treatment consisted of 10 explants and the experiment was repeated three times. Growth characteristics such as callus formation and abnormal shoot formation were observed weekly in each treatment during each subculture and the percentage of explants producing shoots and number of shoots per explant were recorded in each treatment after the third subculture.

Root induction. Individual shoots produced from the best shoot induction treatment measuring $2 \mathrm{~cm}$ in length were transferred to MS media containing 1, 2, 3, and $5 \mu \mathrm{M}$ of either IBA or NAA. Each 
treatment consisted of 10 explants and the experiment was repeated three times. The percentage of explants producing roots and number and length of roots produced per explant were recorded in each treatment after 4 weeks of culture.

Acclimatization. Rooted plantlets produced as described previously were washed
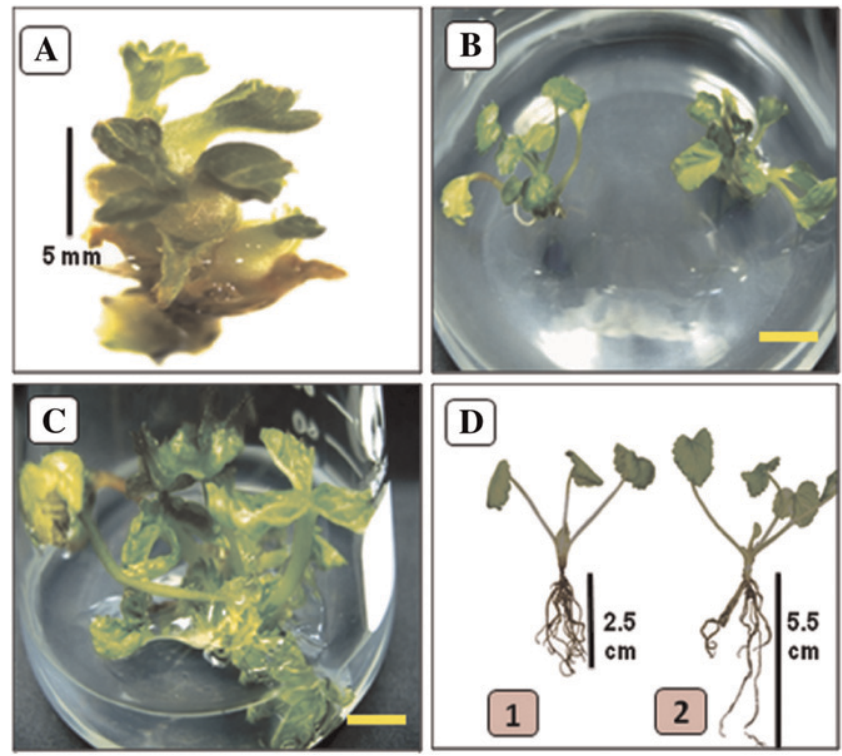

Fig. 1. Shoot proliferation from shoot tips derived from runners of strawberry cv. Camarosa. (A) Shoot tips of in vitro stock plant as the starting material for shoot proliferation. (B) Shoot beginning to proliferate after 1 week of culture on Murashige and Skoog (MS) medium containing $2 \mu \mathrm{M}$ thidiazuron (TDZ) and $4 \mu \mathrm{M}$ N6-benzylamino-purine (BAP) $(\mathrm{Bar}=0.5 \mathrm{~cm})$. (C) Shoot formation on MS medium containing $2 \mu \mathrm{M}$ TDZ and $4 \mu \mathrm{M}$ BAP after 12 weeks of culture (Bars $=1 \mathrm{~cm}$ ). (D) Comparison of root formation 1: High number of roots formed in MS medium with $1 \mu \mathrm{M}$ naphthaleneacetic acid (NAA); 2: high length of root formed in hormone-free MS medium.
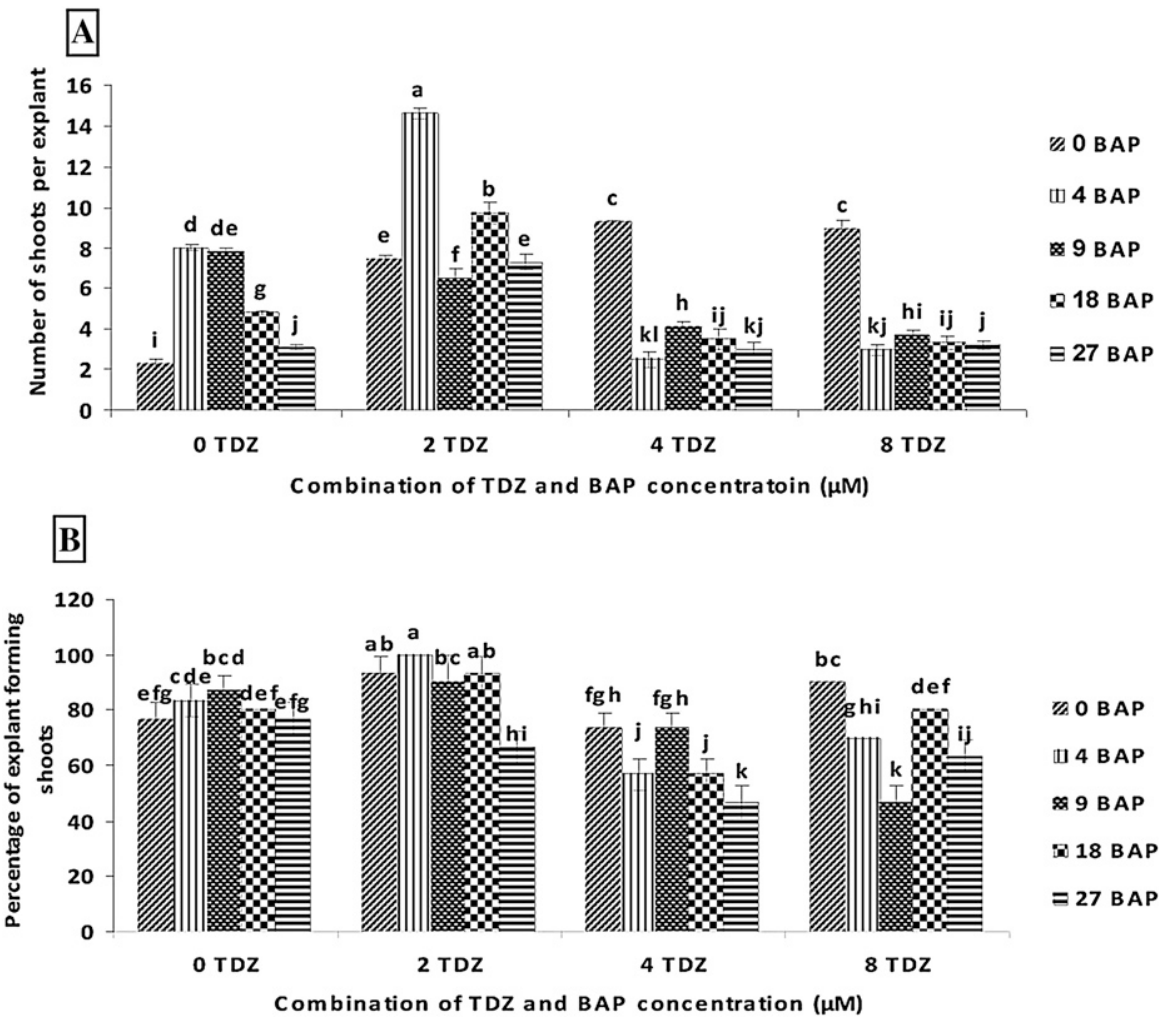

Fig. 2. Effect of thidiazuron (TDZ) in combination with N6-benzylamino-purine (BAP) on (A) number of shoots induced from in vitro shoot tips and (B) percentage of shoots produced from in vitro shoot tips of strawberry cv. Camarosa after 12 weeks of culture. Data represented mean value of three replications. Means followed by the same letter(s) are not significantly different based on Duncan's new multiple range test at $\alpha=0.05$. Bars $=\mathrm{SD}$.

with distilled water and transplanted into holes in trays filled with perlite, vermiculite, and cocopeat $(2: 1: 2 \mathrm{v} / \mathrm{v} / \mathrm{v})$. The plantlets were placed in a misting chamber and misted 5 min with water every $20 \mathrm{~min}$. Misting was then stopped after 1 month and the plantlets were irrigated with quarter-strength Hoagland's solution (Sigma Company) for 3 weeks, half-strength solution for another 3 weeks, and full strength thereafter (unpublished data).

Statistical analysis. Each experiment was arranged in a randomized complete block design and data were analyzed using analysis of variance. When treatments were significant, means were separated at the 5\% level using Duncan's new multiple range test.

\section{Results}

Shoot induction. Shoots began to proliferate after 1 week of culture (Fig. 1B). The number of shoots per explant increased with each 4-week subculture and after 12 weeks was highest on MS medium containing $2 \mu \mathrm{M}$ TDZ with $4 \mu \mathrm{M}$ BAP (Figs. $1 \mathrm{C}$ and $2 \mathrm{~A}$ ). This medium produced an average of 15 shoots per explant and resulted in significantly more shoots than any other treatment. It was also the only treatment in which $100 \%$ of the explants produced shoots (Fig. 2B). By comparison, only $77 \%$ of the explants produced shoots on medium with no TDZ or BAP and averaged only two shoots per explant.

It is interesting to note that increasing the TDZ concentration in the absence of BAP increased the mean number of shoots produced per explant. However, by increasing the BAP concentration in the absence of TDZ, the reverse was observed (Fig. 2A). Poor shoot production also occurred at high concentrations of BAP, especially when 4 or $8 \mu \mathrm{M}$ of TDZ was applied (Fig. 2A). No callus formation was observed in any treatment, although a few treatments with high amounts of TDZ resulted in shoot fasciation and inhibited shoot elongation. Nevertheless, after subculturing to hormone-free MS medium, the shoots elongated with normal appearance.

Root induction. Explants obtained from medium containing $2 \mu \mathrm{M}$ TDZ and $4 \mu \mathrm{M}$ BAP produced callus after 1 week and began initiating roots after $10 \mathrm{~d}$ on media containing NAA, whereas those on media containing IBA also produced callus after 1 week and began to initiate roots after $14 \mathrm{~d}$. Explants also initiated roots after $10 \mathrm{~d}$ on hormonefree MS medium but had no callus tissue. The most number of roots per explant was produced on media containing $1 \mu \mathrm{M}$ NAA or $2 \mu \mathrm{M}$ IBA, which averaged six and five roots per explant, respectively (Figs. 1D and $3 \mathrm{~A}$ ), and $\approx 70 \%$ of the explants produced roots in both treatments (Fig. 3C). Without hormone, explants averaged only three roots per explant with $\approx 68 \%$ of the explants producing roots, but roots were longer in general than in any of the hormone treatments (Fig. 3A-C). Root length averaged $\approx 1.0 \mathrm{~cm}$ without hormone compared 

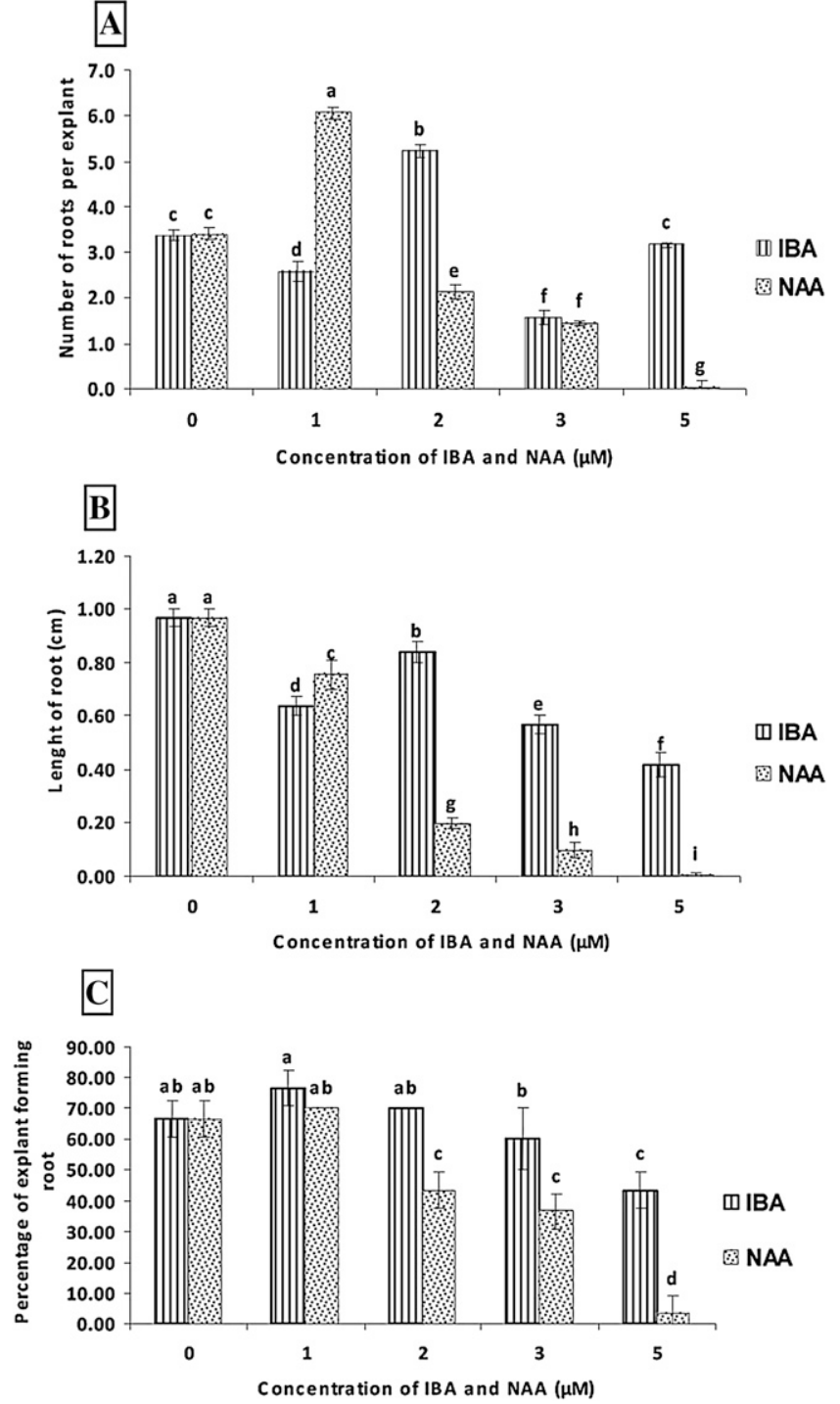

Fig. 3. Effect of indole-3-butyric acid (IBA) and naphthaleneacetic acid (NAA) on (A) number of roots produced per explant; (B) length of root $(\mathrm{cm})$; and $(\mathbf{C})$ percentage of root formation of strawberry cv. Camarosa after 4 weeks of culture. Data represented mean value of three replications. Means followed by the same letter(s) are not significantly different based on Duncan's new multiple range test at $\alpha=$ 0.05 . Bars $=\mathrm{SD}$

with $\approx 0.8 \mathrm{~cm}$ with $1 \mu \mathrm{M}$ NAA and $0.9 \mathrm{~cm}$ with $2 \mu \mathrm{M}$ IBA.

Acclimatization. Approximately $90 \%$ of the explants that were rooted in media with $1 \mu \mathrm{M}$ NAA or $2 \mu \mathrm{M}$ IBA survived after they were transplanted in the misting chamber. The plants began to produce runners after 3 months in the greenhouse and runners were well established and ready for field planting after 6 months.

\section{Discussion}

Tissue culture techniques have the advantage of producing a large quantity of plant materials in a short time compared with the traditional methods of vegetative propagation. This method has many practical and commercial applications in horticulture. Therefore, development of an in vitro cloning protocol of strawberry would provide the way for commercial micropropagation. On a com- widely used for micropropagation of severa woody plants (Huetteman and Preece, 1993). Also, there are reports on the effect of this cytokinin on a few Fragaria Xananassa cultivars (Debnath, 2006).

In this study, results showed that in the absence of BAP, 4 to $8 \mu \mathrm{M}$ TDZ is optimum for production of high number of shoots from shoot tips derived from runners (Fig. 2). Debnath (2006) reported on lower concentrations of TDZ ( 2 to $4 \mu \mathrm{M}$ ) to promote shoot proliferation from sepal-derived adventitious shoots of 'Bounty' strawberry (Fragaria xananassa Duch.). This confirmed that explant types and cultivars of different genetic background may give different regeneration responses. In this study, the combination of moderate concentrations of $2 \mu \mathrm{M} \mathrm{TDZ}$ and $4 \mu \mathrm{M}$ BAP promoted a high percentage of shoot tip explant producing shoots $(100 \%)$ at an average of 15 shoots per explant. It showed that plant growth regulators (PGRs) rarely act alone and for most processes, many of these regulators have interacted to produce the final effect (Gaspar et al., 1996). Also by using a low concentration of TDZ (a PGR with high cytokinin activity), less BAP is needed. Meanwhile, Sakila et al. (2007) reported using $7 \mu \mathrm{M}$ BAP in medium with 0.5 to $2 \mu \mathrm{M}$ kinetin for micropropagation from nodal segments of strawberry.

Several setbacks have been encountered at high concentrations of cytokinins such as reduction in the number of micropropagated shoots (Naik et al., 1999), shoot fasciation (Huetteman and Preece, 1993), and inhibition of shoot elongation (Debnath, 2005). Shoot fasciation was usually caused by high concentrations of TDZ as an efficacious bioregulant for morphogenesis rather than other cytokinins (Arinaitwe et al., 2000). Those results may relate to the high stability of TDZ in plant tissue (Mok et al., 1982) and its high cytokinin activity (Huetteman and Preece, 1993; Mok et al., 1982), which causes accumulation of endogenous cytokinin that inhibits the action of cytokinin oxidase (Hare et al., 1994). In addition, it may be the result of other possibilities such as modification in cell membranes, energy levels, nutrient uptake, or nutrient assimilation caused by TDZ (Murthy et al., 1998).

In this study, inhibition of shoot elongation and reduced number of micropropagated shoots occurred in all treatments with high concentrations of TDZ and BAP either alone or in combination. Results showed that after subculturing the stunted shoots on hormonefree MS medium, shoots elongated with normal appearance. According to Naik et al. (1999), to overcome the inhibition of shoot elongation, shoots should be transferred to medium often without hormone or with a different growth regulator. In some cases, shoots can be transferred to less active cytokinin for shoot elongation (Huetteman and Preece, 1993). According to Sutter et al. (1997), inhibition of elongation occurred at $10 \mu \mathrm{M}$ BAP for strawberry 'Pajaro', but the shoots elongated and grew normally when the BAP concentration was reduced by half. 
In this study, some visual differences were observed between shoots induced on TDZ and those on BAP. The length of shoots from medium with a moderate concentration of BAP $(4 \mu \mathrm{M})$ was higher than that of shoots obtained on $4 \mu \mathrm{M}$ TDZ. However, the number of shoots produced with TDZ was higher than on BAP of the same concentration. Such occurrence could be the result of the higher cytokinin activity of TDZ in comparison with BAP (Huetteman and Preece, 1993; Mok et al., 1982) and reliance of shoot organogenesis on a physiologically more active compound like TDZ in the medium (LingFei et al., 2008). In this study, no significant difference was found between the concentrations of 4 and $8 \mu \mathrm{M}$ TDZ on mean number of shoots produced per explant; nonetheless, it is more economical to use $4 \mu \mathrm{M}$ TDZ.

Root induction. The types and concentrations of auxins have different effects on root induction, percentage of explant forming roots, and length of roots produced per explant. In this study, among the highest percentages of root formation were in MS medium containing $1 \mu \mathrm{M}$ IBA, $1 \mu \mathrm{M}$ NAA, $2 \mu \mathrm{M}$ IBA, and MSO (Fig. 3C). Sutter et al. (1997) found that to get up to $100 \%$ rooting, strawberry shoots should be placed on medium with low concentrations of BAP and IBA for 1 month and then transferred to medium with $5 \mu \mathrm{M}$ IBA. In another report, Husaini and Srivastava (2006) showed that using half-strength MS medium with $5 \mu \mathrm{M}$ IBA produced a high percentage of rooting for strawberry. However, in this study, using full-strength MS medium and increasing the concentration of IBA from $1 \mu \mathrm{M}$ to $5 \mu \mathrm{M}$ caused reduction in percentage of root formation and an increase in callus induction. Moreover, in all treatments with IBA, the roots produced were thicker than in the control, similar to the result reported by Bhatt and Dhar (2000).

This study showed that an average of six roots per explant was produced in a low concentration of $1 \mu \mathrm{M}$ NAA (Fig. 3A). However, in $5 \mu \mathrm{M}$ NAA, callus covered the shoot causing poor ability to form roots. Similarly increasing the NAA concentration from 1 to $5 \mu \mathrm{M}$ reduced the percentage of rooting. These results are in accordance with Bhatt and Dhar (2000) who reported that $1 \mu \mathrm{M}$ NAA was the best concentration of NAA to induce $\approx 97 \%$ roots for Indian strawberry. Also, they found that by increasing the concentration of NAA, lower percentage and number of roots per explant were obtained. In general, production of callus in the presence of IBA and NAA may cause inhibition of root elongation because the callus covered the shoot and inhibited root emergence from the shoot. In this study, the highest length of root was produced in medium without IBA or NAA and the lowest length of root was in high concentration of $5 \mu$ M NAA. Debnath (2005) showed that MS medium without hormone produced suitable roots for acclimatization of strawberry plant (Debnath, 2005). Overall, based on our results, MS medium containing $2 \mu \mathrm{M}$ IBA would be more suitable for acclimatization of 'Camarosa' strawberry as a result of the production of moderately high number of roots, length, and percentage of rooting.

Acclimatization. Our results showed that the substrate composed of perlite, vermiculite, and cocopeat $(2: 1: 2 \mathrm{v} / \mathrm{v} / \mathrm{v})$ resulted in $90 \%$ plant survival and after irrigation using Hoagland's solution, runners were produced. Interestingly, for those plants that were not irrigated with Hoagland's solution, their growth was very slow and only a limited number of runners was produced after 6 months, thus confirming the effectiveness of Hoagland's solution on runner production. Medina et al. (2007) successfully acclimatized strawberry plantlets by transplanting them into trays filled with peat-perlite (1:1 $\mathrm{v} / \mathrm{v}$ ) and placing the trays under a transparent polypropylene cover with $90 \%$ relative humidity for 3 weeks. The plants were individually transferred to pots with peat, sand, and perlite $(7: 2: 1)$ for another 3 weeks.

\section{Conclusion}

Overall, hormone free MS medium, MS medium containing $2 \mu \mathrm{M} \mathrm{TDZ}$ and $4 \mu \mathrm{M}$ BAP and MS medium with $2 \mu \mathrm{M}$ IBA were the most suitable media for producing in vitro stock plants, shoot induction and multiplication, and rooting of shoots of strawberry $\mathrm{cv}$. Camarosa, respectively. Plantlets were successfully acclimatized in substrate consisting of perlite + vermiculite + cocopeat $(2: 1: 2 \mathrm{v} / \mathrm{v} /$ v). Runner production began 3 months after irrigation using Hoagland's solution and runners were well established and ready for field planting after 6 months.

\section{Literature Cited}

Arinaitwe, G., P.R. Rubaihayo, and M.J.S. Magambo. 2000. Proliferation rate effects of cytokinins on banana (Musa spp.) cultivars. Sci. Hort. 86:13-21.

Bhatt, I.D. and U. Dhar. 2000. Micropropagation of Indian wild strawberry. Plant Cell Tissue and Organ Culture. 60:83-88.

Boxus, Ph. 1974. The production of strawberry plants by in vitro micropropagation. J. Hort. Sci. 49:209-210.

Debnath, S.C. 2005. Strawberry sepal: Another explant for thidiazuron-induced adventitious shoot regeneration. In Vitro Cell. 41:671-676.

Debnath, S.C. 2006. Zeatin overcomes thidiazuroninduced inhibition of shoot elongation and promotes rooting in strawberry culture in vitro. The Journal of Horticultural Science and Biotechnology. 81:349-354.

Gaspar, T., C. Kevers, C. Penel, H. Greppin, D.M. Reid, and T.A. Thorpe. 1996. Plant hormones and plant growth regulators in plant tissue culture. In Vitro Cell. Dev. Biol. Plant 32:272-289.

George, E.F. 1996. Plant propagation by tissue culture. Part 2. Exegetics, Edington, UK.

Hare, P.D., J. Staden, and J. Van Staden. 1994. Inhibitory effect of TDZ on the activity of cytokinin oxidase isolated from soybean callus. Plant Cell Physiol. 35:1121-1125.

Huetteman, C.A. and J.E. Preece. 1993. Thidiazuron: A potent cytokinin for woody plant tissue culture. Plant Cell Tissue Organ Cult. 33:105-119.

Husaini, A.M. and D.K. Srivastava. 2006. Plant regeneration and agrobacterium-mediated gene transfer studies in strawberry tissues (Fragaria Xananassa Duch.). Asian Journal of Microbiology Biotechnology and Environmental Sciences 8:671-678.

Landi, L. and B. Mezzetti. 2006. TDZ, auxin and genotype effects on leaf organogenesis in Fragaria. Plant Cell Rep. 25:281-288.

LingFei, X., M. FengWang, and L. Dong. 2008. Plant regeneration from in vitro cultured leaves of Lanzhou lily (Lilium davidii var. unicolor). Sci. Hort. 119:458-461

Lopez-Aranda, J.M., F. Pliego-Alfaro, I. LopezNavidad, and M. Barcelo-Munoz. 1994. Micropropagation of strawberry (Fragaria Xananassa Duch.). Effect of mineral salts, benzyladenine levels and number of subcultures on the in vitro and field behaviour of the obtained microplants and the fruiting capacity of their progeny. J. Hort. Sci. 69:625-637.

Medina, J.J., I. Clavero-Ramirez, M.E. GonzalezBenito, J. Galvez-Farfan, J.M. Lopez-Aranda, and C. Soria. 2007. Field performance characterization of strawberry (Fragaria Xananassa Duch.) plants derived from cryopreserved apices. Sci. Hort. 113:28-32.

Mohamed, F.H., M.S. Beltai, M.A. Ismail, and G.F. Omar. 2007. High frequency, direct shoot regeneration from greenhouse-derived leaf disks of six strawberry cultivars. Pak. J. Biol. Sci. 10:96-100.

Mok, M.C., D.W.S. Mok, J.E. Turner, D.J. Armstrong, K. Shudo, Y. Isogai, and T. Okamoto. 1982. Cytokinin activity of N-phenyl-N'-1,2,3,-thiadiazol-5ylurea (thidiazuron). Phytochemistry 21:1509-1511.

Murashige, T. and F. Skoog. 1962. A revised medium for rapid growth and biossays with tobacco tissue cultures. Physiol. Plant. 15:473497.

Murthy, B.N.S., S.J. Murch, and K.P. Saxena. 1998. Thidiazuron: A potent regulator of in vitro plant morphogenesis. In Vitro Cell. Dev. Biol. Plant 34:267-275.

Naik, S.K., S. Pattnaik, and P.K. Chand. 1999. In vitro propagation of pomegranate (Punica granatum L. cv Ganesh) through axillary shoot proliferation from nodal segments of mature trees. Sci. Hort. 79:175-183.

Passey, A.J., K.J. Barrett, and D.J. James. 2003. Adventitious shoot regeneration from seven commercial strawberry cultivars (Fragaria Xananassa Duch.) using a range of explant types. Plant Cell Rep. 21:397-401.

Sakila, S., M.B. Ahmed, U.K. Roy, M.K. Biswas, R. Karim, M.A. Razvy, M. Hossain, R. Islam, and A. Hoque. 2007. Micropropagation of strawberry (Fragaria Xananassa Duch.). A newly introduced crop in Bangladesh. American-Eurasian Journal of Scientific Research 2:151-154.

Sutter, E.G., H. Ahmadi, and J.M. Labavitch. 1997. Direct regeneration of strawberry (Fragaria Xananasa Duch.) from leaf disks. Acta Hort. 447:243-245.

Svensson, M. and L.B. Johansson. 1994. Anther culture of Fragaria $\times$ ananassa: Environmental factors and medium components affecting microspore divisions and callus production. $\mathrm{J}$. Hort. Sci. 69:417-426.

Yonghua, Q., Z. Shanglong, S. Asghar, Z. Lingxiao, Q. Qiaoping, C. Kunsong, and X. Changjie. 2005. Regeneration mechanism of Toyonoka strawberry under different color plastic films. J. Peanut Sci. 168:1425-1431. 